\title{
$14.4 \mathrm{~m}$ LARGE APERTURE ANALYSIS MAGNET WITH ALUMINUM COILS
}

\author{
R.W. Fast*, E.W. Bosworth ${ }^{\star}$, C.N. Brown ${ }^{\star}$, D.A. Finley ${ }^{\dagger}$ \\ A.M. Glowacki*, J.M. Jagger ${ }^{\star}$ and S.P. Sobczynski*
}

Abstract - A $14.4 \mathrm{~m}$ horizontal field particle analysis magnet, with an aperture $930 \mathrm{~mm}$ horizontal $x 1200 \mathrm{~mm}$ vertical has been designed at Femilab and is presently under construction. The flux return yoke $(1200 \mathrm{t})$ is fabricated from the yoke of the Nevis cyclotron. The window frame coils provide $813 \mathrm{kA}$-turns at $4.15 \mathrm{kA}$. Aluminum conductor, $61.5 \mathrm{~mm}$ square, was extruded in $11 \mathrm{~m}$ lengths, bent and weided to form turns and layers. The turns were insulated with B-staged epoxy glass tapes cured under pressure.

\section{INTRODUCTION}

The conventional dipole magnet described in this paper is presently being fabricated and assembled at the Fermi National Accelerator Laboratory. The large aperture and $30 \mathrm{~T}-\mathrm{m}$ field integral of the magnet form the basis of a focusing spectrometer which will be used to conduct incisive observations of fundamental

interactions. Although the experimental criteria fix the basic parameters of the magnet, a prime consideration at each step in the design has been to minimize the cost. The remainder of this paper describes the resulting design of the aluminum coils and the steel return yoke.

\section{RETURN YOKE DESIGN AND FABRICATION}

\section{Yoke Requirements}

Physics requirements necessitated a horizontal field and an aperture $930 \mathrm{~mm}$ horizontal $\times 1200 \mathrm{~mm}$ vertical $\times 14.4 \mathrm{~m}$ long into which tapered poles, a beam dump and absorbers may be inserted. The steel from the cyclotron at the Nevis Laboratory of Columbia University was to be used for the return yoke.

\section{Yoke Design}

The yoke was designed to minimize cutting and machining of the Nevis steel. The weight of the yoke is $1200 \mathrm{t}$, of which $98 \%$ came from the cyclotron. The yoke is shown in Fig. 1. Stainless steel shelves will bridge the aperture, fitting into horizontal, longitudinal milled cuts in the yoke. These shelves support the upper coils and the aperture inserts.

\section{Yoke Fabrication}

The 1800 t Nevis magnet yoke, built in 1947-1950, was composed of 38 machined steel forgings, the heaviest of which weighed $54 \mathrm{t}$. This steel is used for the yoke of the new magnet. The top, and bottom, of the Nevis yoke was assembied from 10 pieces of steel each measuring $432 \mathrm{~mm} \times 1600 \mathrm{~mm} \times 10 \mathrm{~m}$. These pieces, with the $10 \mathrm{~m}$ length cut in half, are utilized to form the upright portions of the new return yoke. Each side of the Nevis yoke contained five pieces of steel, each $864 \mathrm{~mm} \times 1600 \mathrm{~mm} \times 3200 \mathrm{~mm}$. The $3200 \mathrm{~mm}$ length was cut to give two pieces $997 \mathrm{~mm}$ long, which are used for the bottom and top center of the dipole yoke.

The yoke pieces were cut at Nevis using a comercial flame cutting machine. Oxygen for cutting was

*Fermi National Accelerator Laboratory, Batavia, IL. 60510 , USA. Work supported by U.S. Dept. of Energy.

tState University of New York, Stony Brook, NY. 11794, USA.

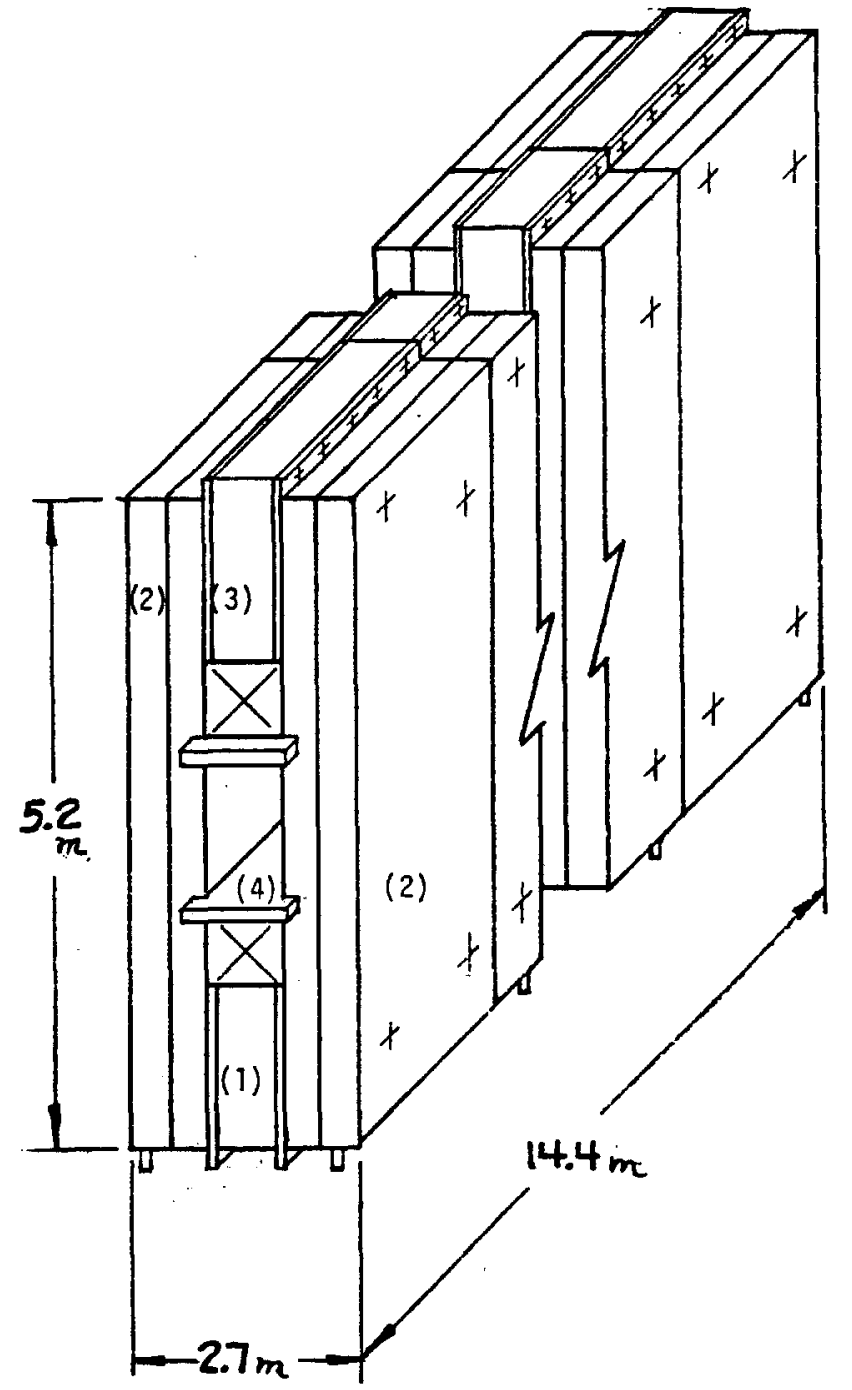

Fig. 1. Steel return yoke. (1) are lower center yoke blocks, (2) are uprights, (3) are upper center yoke blocks, (4) is aperture shelf.

supplied either from a liquid dewar or a high pressure tube trailer. The cutting began by preheating the leading edge of the steel for $\sim 10 \mathrm{~min}$. The cutting machine was then turned on and set to travel at a speed of $0.85 \mathrm{~mm} / \mathrm{s}$. The speed was reduced for the last $100 \mathrm{~mm}$ of the cut.

The steel was shipped by truck from New York to a Chicago fabricator where it was machined. The cut pieces had a residual radioactivity level of $<3 \mathrm{mrad}$ on contact, which required only that Fermilab have a radiation safety technician check at intervals during fabrication and that the machining chips be collected. 
COIL DESIGN

\section{Coil Requirements}

The design goal was for a water-cooled coil of at least $800 \mathrm{kA}$-turns within a 5000A, 300V power supply limitation. The iron design resulted in a total coil window $930 \mathrm{~mm}$ square, shown in Fig. 2. In order to

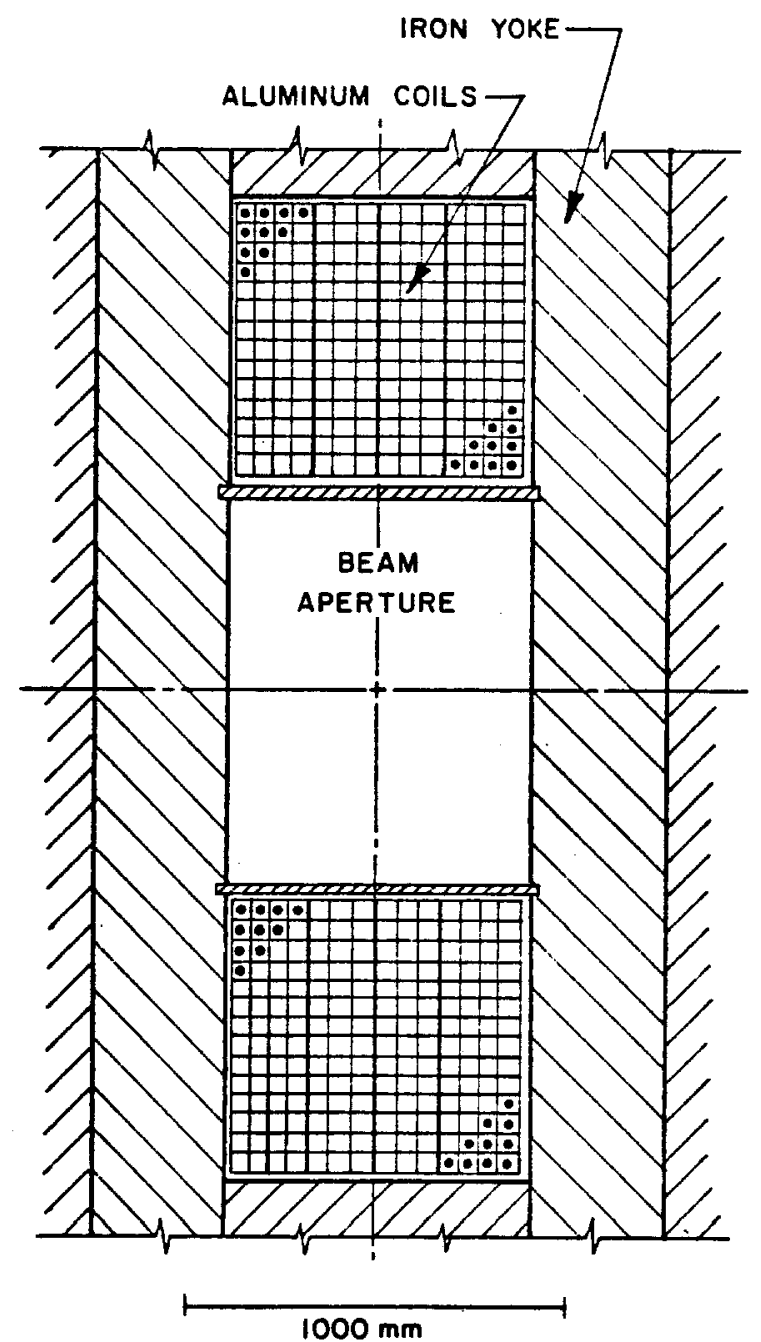

Fig. 2. Coil cross section

reduce the amount of the coil which extends past the iron, $45^{\circ}$ horizontal bends were chosen. Due to the long length of the magnet it was considered impractical to wind the coils in the conventional manner. It was decided to use a bend and weld technique where short lengths of conductor are first bent and then sequentially butt welded to form turns and layers. Since it will be very expensive to repair the coils after installation, fong term reliability is also a requirement. The lifetime of the magnet is estimated to be in excess of 10 years.

\section{Coil Parameters}

The choice between copper and aluminum as the conductor material was made on the bas is of total cost, i.e., conductor cost plus fabrication cost. The conductor cost may be analayzed with a figure of merit
$(F O M)=(N I)^{2} /($ conductor cost $x$ magnet power $)$. In this case the FOM $=\left[(\right.$ density $)\left(\right.$ cost/weight) $(\text { resistivity) }]^{-1}$ and is obviously larger for aluminum. It was determined on the basis of experience at SLAC with aluminum and at Fermilab with copper that the fabrication costs are approximately equal. Aluminum was therefore chosen as the conductor material for this magnet. The conductor is shown in Fig. 3, and the coil design parameters are shown in Table I.

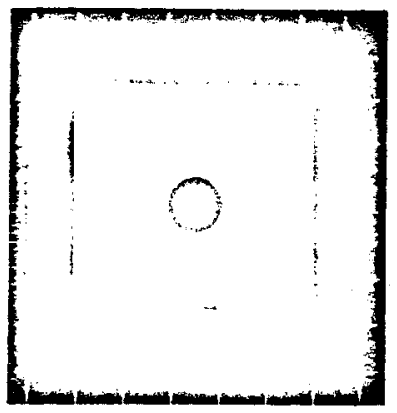

Fig. 3. Aluminum conductor

Table I. Coil Design Parameters
Conductor:

Conductor required:

Turns per layer:

Total turns:

Power supply voltage:

Max. expected $\mathrm{I}$ and $\mathrm{J}$ :

Max. expected excitation:

Total power:

Inlet water temp \& $\Delta T$ :

Water flow: a) uminum, $61.5 \mathrm{~mm} \mathrm{sq} \times 14 \mathrm{~mm} \phi$ $69.1 \mathrm{t}, 7.85 \mathrm{~km}$ 14 196 300 circuit is voltage limited $4150 \mathrm{~A}$ and $1.75 \mathrm{~A} / \mathrm{mm}^{2}$ 813 kA-turns $1200 \mathrm{~kW}$ $38 \mathrm{C}$ and $17 \mathrm{C}$ 1000 liters/min
Thermal and Magnetic Stress Analys is

The conductors in the $14.4 \mathrm{~m}$ straight section of the coil are subjected to both thermal and magnetic stresses. At design current adjacent conductors are magneticaliy clamped to each other with a force which varies from $75.7 \mathrm{kN}(7.7 \mathrm{t})$ for the inner conductors to $546.4 \mathrm{kN}(55.8 \mathrm{t})$ for the conductors next to the iron. These forces prevent relative motion between conductors or between conductors and iron as turn-to-turn temperature differences are established. The maximum compressive thermal stress in an elastic conductor is 27.6 MPa, if the coil is permitted to reach the iniet water temperature (38C) before the magnet is energized.

In order to preclude long term damage to the conductor through multiple yielding, the conductor material and welding procedure are such that the magnetically clamped bars remain elastic. The bus conductor alloy 6101-T63 [1] was chosen since it has an elastic limit greater than $70 \mathrm{MPa}$. The electrical conductivity of this alloy is greater than $57 \%$ IACS [2] ( $\left.3 \times 10^{-8} \Omega-m\right)$. Since the turns all have butt welds in the straight sections, a weld procedure has been chosen to insure that the weld heat affected zone behaves elastically to at least $35 \mathrm{MPa}$. To reduce the themal stresses by a factor of two, the magnet operating procedure includes that the magnet be momentarily de-energized at intervals during the warm-up time.

\section{Insulation}

The insulation in this coil is quite thick to provide mechanical protection against fabrication errors. Inter-turn metal chips and undetected burrs on the conductor are unlikely to cause electrical shorts. Each conductor bar first is wrapped with a half-lapped layer 
of $0.18 \mathrm{~mm}$ poiyester-glass tape impregnated with Bstaged epoxy resin. The bar is then butt wrapped with $0.75 \mathrm{~mm} 3 \mathrm{M}$ Scotchply, a non-woven fiberglass-reinforced B-staged epoxy resin composite. The coil, or ground wrap is the same as the conductor wrap but with the polyester-glass tape on the outside. Upon curing, the resin flows into crevices and forms a monolithic structure. The total insulation between adjacent conductors or between conductor and iron is $2.24 \mathrm{~mm}$.

Since the magnet has a beam dump in the aperture, the question of radiation damage to the coil, especially to the insulation, is relevant. The coil is approximately $600 \mathrm{~mm}$ from the dump. Caiculations [3] give a worst-case energy deposition of $2.1 \times 10^{8}$ rads per $10^{18} 400 \mathrm{GeV}$ protons absorbed by the dump. Shielding the coils with $25 \mathrm{~mm}$ of lead reduces this by a factor of ten. The worst-case dose rate expected is $10^{8} \mathrm{rads} /$ year and $10^{9}$ rads over the life of the magnet. Radiation induced degradation of mechanical and electrical properties of fiberglass reinforced epoxy used for coil insulation is not significant below $210^{21}$ rads [4].

\section{Corrosion [5]}

Aluminum is anodic to copper, and therefore aluminum coils are susceptible to galvanic corrosion when cooled with water systems which are also used for copper coils. De-ionizing the low conductivity water system to $0.5 \times 10^{-4} \mathrm{mho} / \mathrm{mm}$ prevents corrosion. In order to guard against dissimilar metal corrosion, all water fittings and pipes inside the coil are made from the same alloy as the conductor. The aluminum water pipes terminate in accessible stainless steel fittings for connection through rubber hoses to the water system. Impingement and cavitation corrosion rates are insignificant for systems with low flow velocity and de-ionized water.

\section{Water and Electrical Connections}

In order to reduce the likel ihood of long term water induced coil damage caused by leaking fittings or burst hoses, all water connections are located near the floor. As a safety measure, the electrical connections are made at the top of the coil, approximately $4 \mathrm{~m}$ from the floor.

\section{COIL FABRICATION}

\section{Basic Technique}

The construction of the coils proceeds serially as follows:

1) Extrude and deliver conductor in $11 \mathrm{~m}$ lengths.

2) Bend and weld to form layer (14 turns, 112 bends, 56 welds) at outside vendor, deliver to Fermilab.

3) Apply conductor insulation.

4) Weld joints between layers to form 3 or 4 layer coils.

5) Apply ground insulation, clamp and cure.

6) Deliver two 3-layer and two 4-layer coils to the Meson Area for installation.

\section{Aluminum Conductor}

The aluminum conductor is specified for alloy and heat treatment and for mechanical and electrical properties. Standard tolerances [3] are specified on the over-all size, hole diameter and placement, flatness, twist, etc. The 789 pieces of conductor are ordered in four discrete lengths. The conductor is extruded from billets $305 \mathrm{~mm} \phi \times 660 \mathrm{~mm}$ on a $2700 \mathrm{t}$ press, stretched, cut to length and heat treated. The solution heat treatment consists of a water quench immediately following extrusion. The precipitation heat treatment to obtain the - T63 condition is $9 \mathrm{~h}$ at 210C. The measured yield strength of the finished conductor is $163-220 \mathrm{MPa}$. The electrical conductivity is $57-61 \%$ IACS. The dimensions are all better than specified.

\section{Fabrication of Single Layer}

It is recognized that two critical factors in coil fabrication are that the coils must fit into the iron window and that the layers must nest. The conductor packing density in the coil ends is reduced to permit the fabrication tolerances to be relaxed. For example, adjacent turns in the straight section are 2.3 to 3.6 $\mathrm{mm}$ apart while in the end section the separation is $6.4-12.7 \mathrm{~mm}$. The $45^{\circ}$ bends are dekeys toned to meet the straight section separation. The four welds in each turn are located in the straight and end sections, making it easier to meet the tolerances. The tolerance on the long straight dimensions is $\pm 6.35 \mathrm{~mm}$. The most critical dimension in a layer is the inside transverse distance, which is held to $\pm 1.6 \mathrm{~mm}$ in order to fit into the magnet. A typical layer is shown in Fig. 4. The individual layers are dimensioned to provide space between layers on the ends so the $90^{\circ}$ bends are not dekeystoned. The spaces on end end were larger to accommodate the water pipes which reach inside the coil. All the water piping is located on the downstream end.

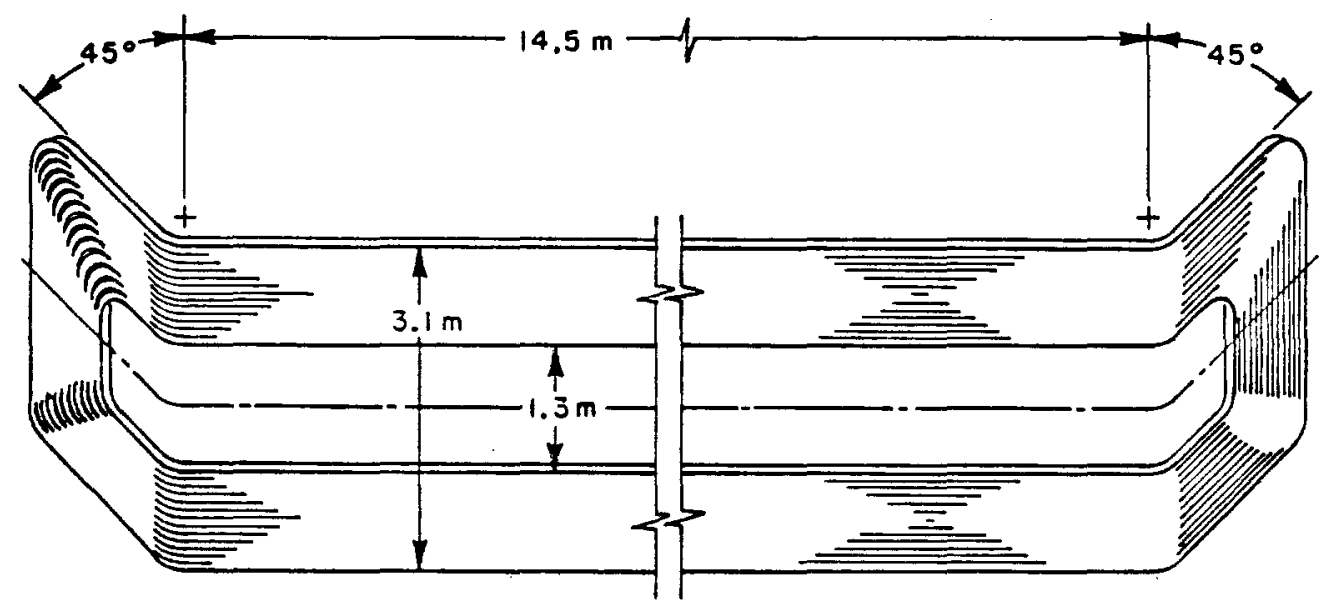

Fig. 4. Single Layer 
A 6101-T63 weld sleeve is used to el iminate weld penetration into the cooling water hole, to assist with alignment and to provide a continuous water path of conductor terial. The 780 butt welds made by the vendor undergo a four part inspection: (1) An $11 \mathrm{~mm}$ ball is biown through the conductor to check for obstructions in the water flow patin. (2) The weid is leak tested to the provisions of the ASME Boiler Code [6]. (3) The weld is hydrostatically tested to a pressure of $4 \mathrm{ma}$ in accordance with the code [7]. (4) The weld is radiographed in accordance with the Code [8].

\section{Assembly of Layers into 3 and 4 Layer Coils}

The layers are assembled into coils at Fermilab. An $18 \mathrm{~m}$ assembly and curing fixture is used to maintain dimensions. The first layer is placed $\sim 1 \mathrm{~m}$ above the fixture with the ends directed upward. Starting on the inside the turns will be spiraled downward, wrapped with insulation and lowered to the fixture. The water pipes (26.7 mm OD $\times 18.8 \mathrm{~m}$ ID) are welded in place, inspected [6] [7] and insulated. Subsequent layers are assembled on top of each other. The coils are ground wrapped with insulation. Steel curing plates $12 \mathrm{~mm}$ thick are installed on all four sides of the straight and the end sections and preloaded to provide a curing pressure.

The coil will be heated to the curing temperature by passing a $D C$ current through the conductor. This technique for curing coil insulation has not been used at Fermilab for coils of this size. Consequentiy, the heating, steady-state curing and cooling phases were analyzed. Based on calculations, the coil to be cured (including the steel clamping plates) is wrapped in a $100 \mathrm{~mm}$ fiberglass wool insulating blanket and heated with a $400 \mathrm{~kW}$ power supply. Approximately $3500 \mathrm{MJ}$ of heat are added to raise the temperature of a four layer package from $20 \mathrm{C}$ to the curing temperature of $150 \mathrm{C}$. Most of this thermal energy $(72 \%)$ is in the aluminum; the remaincter is in the steel clamping plates $(17 \%)$, in the insulation (6\%) and in the fiberglass blanket (5\%). The thermal inertia of the metal prevents large or sudden temperature changes. With this power supply, it takes approximately $3 \mathrm{~h}$ to heat a four layer package to the curing temperature. The power supplied is not constant, and the resistance of a coil changes by $40 \%$ as the temperature rises. Once $150 \mathrm{C}$ is reached, heat loss through the blanket is 28 kilowatts and $560 \mathrm{~A}$ is adequate to maintain the temperature. At $150 \mathrm{C}$ a $1 \mathrm{~A}$ change in the current causes a temperature change of थ 0.6C. It is necessary to keep the insulation at as nearly a uniform temperature as possible during the various phases of the process (heating, curing, cooling). in each phase the maximum temperature difference occurs across the ground wrap. While heating, the maximum temperature difference is less than $5.5 \mathrm{C}$. During the three hour curing phase, this maximum is $\approx 0.5 \mathrm{C}$. The blanket is removed during the cooling phase so that the coil and steel clamping plates can cool more quickly. During this phase, the maximum temperature difference is less than $8.5 \mathrm{C}$. With natural convection and radiation heat transfer, it takes about 4 hours to decrease the temperature to $100 \mathrm{C}$, and 36 hours to reach 26C. Forced convection is provided after $\approx 8 \mathrm{~h}$ to shorten the cooling time. Following the curing process, the layer-to-layer spaces in the coil end sections are filled with a loaded epoxy and cured at room temperature. Each completed 3-layer coil weighs $~ 18$ t and each 4-layer coil $\sim 23 \mathrm{t}$

\section{YOKE AND COIL INSTALLATION}

The assembly of the magnet in the Meson Detector Building began in March 1981 in a pit $\sim 1 \mathrm{~m}$ below floor level. The pit floor, I m thick reinforced concrete, provides longitudinal stiffness for the magnet and distributes the weight. Steel base plates, leveled and grouted, provide a common plane for all magnet components. Assembly begins with the installation of nine lower center yoke blocks, Fig. 1. They are aligned and welded to each other as well as to the base plates. A double wall of 18 uprights are erected on the east side of the center blocks. They are bolted and welded to each other and to the center blocks to provide stability. The stainless steel aperture shelves are installed and supported by temporary brackets.

Each completed coil is moved out of the assembiy building, and a handling and installation fixture attached. The fixture, made of 5083 aluminum alloy [1] weighs $4 \mathrm{t}$. The coil and fixture are loaded on a $18 \mathrm{~m}$ trailer with a straddle lift and moved $\sim 2.5 \mathrm{~km}$ to the Detector Building. The fixture is used to rotate the coil $90^{\circ}$ and install it into the partially assembled iron yoke. The field welds between coils are then made. With the coils in place the nine upper center yoke blocks are installed and bolted to the east uprights. The remaining 18 uprights are erected to form the west wall which is bolted to the rest of the steel.

Connection of electrical bus, cooling water hoses and thermal interlock switches completes the installation.

\section{OTHER COMPONENTS}

The magnet aperture has inserts containing tapered pole faces, a beam dump and non-ferrous absorbers. The inserts are modularized in length and are removable for servicing. The beam aperture increases from $75 \mathrm{~mm}$ horizontal $\times 305 \mathrm{~mm}$ vertical at the entrance to $910 \mathrm{men}$ horizontal $\times 1200 \mathrm{~mm}$ vertical at the exit.

\section{ACKNOWLEDGMENTS}

The authors wish to thank D.P. Eartly, A.S. Ito and A.M. Jonckheere for their valuable assistance. The staff of the Fermilab Magnet Facility is commended for its work on the design and assembly of the coils. The Meson Department design group did the design of the return yoke.

\section{REFERENCES}

I Aluminum Standards and Data, 1979, Washington,D.C., Aluminum Association, Inc.

2 International Annealed Copper Standard.

3 S. Childress, "CASIM Calcuiations of Energy Deposition in M12 Coils", Fermilab 1979 (unpublished).

4 H. Brechna, "Effect of Nuclear Radiation on Organic Materials; Specifically Magnet Insulations in High Energy Accelerators, "Stanford Linear Accelerator Center Report SLAC-40, 1965, Stanford, CA, USA.

5 H.P. Godard, W.B. Jepson, M.R. Bothwel1, R.L. Kane, The Corrosion of Light Metals, New York, John WiTey and Sons.

6 American Society of Mechanical Engineers (ASME) Boiler and Pressure Vessel Code, Section $V$, Article 10, Paragraph 1020, 1030, New York, ASME, 1977.

7 ASME Boiler and Pressure Vessel Code, Section VIII, Div. 1, Paragraph UG-99, New York, ASME, 1977.

8 ASME Boiler and Pressure Vessel Code, Section $V$, Article 2, New York, ASME, 1977. 